\title{
COMUNIDADE TRADICIONAL: conviver, criar, resistir
}

\section{traditional community: coexist, create, resist}

\author{
Carlos Rodrigues Brandão ${ }^{1}$ \\ Alessandra Leal ${ }^{2}$ \\ aaaa
}

\section{Resumo}

Trataremos neste texto do conceito da categoria comunidade tradicional e como o contexto das comunidades nortemineiras pode re-significar tal conceito. Trilhamos as linhas já fundamentadas de José de Souza Martins, Manuela Carneiro da Cunha, Antonio Carlos Diegues, Homni Bhabha, dentre outros. Com eles, dialogamos para concluir que: as comunidades não se fazem "tradicionais" por meio de alguns traços 'folclorizáveis de sua cultura. Elas se tradicionalizam como uma estratégia de defesa. Como um modo de existir dividido entre a relação dependente do "mundo de fora" e uma protegida quase-invisibilidade. Índios, quilombolas, camponeses antes e agora vivendo sob o peso de contínuas ameaças, resistem procurando também fazerem-se invisíveis aos olhos do outro.
\end{abstract}

Palavras-chave: Comunidade tradicional, Território, Fronteira, Populações.

\begin{abstract}
We will treat in this paper about the concept of traditional community category and how the context of communities called "nortemineiras" can re-signify such a concept. We'll follow lines already grounded by José de Souza Martins, Manuela Carneiro da Cunha, Antonio Carlos Diegues, Homni Bhabha, among others. With them, we dialogue to conclude that the communities do not make themselves "traditional" through some 'folklorizable' traces of their culture. They tradicionalize themselves as a defense strategy. As a way of exist being divided between the dependent relationship of the "outside world" and a protected near-invisibility. Indians, quilombolas, peasants, before and now living under the weight of constant threats, resisting trying also to make themselves invisible to the sight of the other.
\end{abstract}

Key words: Traditional community, Territory, Border populations.

\section{Résumé}

Nous allons prendre en compte, dans ce texte, le concept de communauté traditionnelle et comme le contexte des collectivités nortemineiras peut changer le sens des concepts. Parcourions les lignes déjà fondé par José de Souza Martins, Manuela Carneiro da Cunha, Antonio Carlos Diegues, Homni Bhabha, entre autres. Avec eux, nous dialoguons pour conclure que : les communautés ne faisent pas «traditionnel» par le biais 'folclorizáveis' quelques traces de leur culture. Elles se fondent traditionnelle comme une stratégie de défense. Comme une façon d'exister divisée entre la relation de dépendance du «monde extérieur» et une protectrice quasi-invisibilité vis-à-vis les autres.

Palabras clave: Communauté, Communauté traditionnelle, Frontière, Populations.

(1) Prof. Dr. do Programa de Pós-Graduação em Geografia da Universidade Federal de Uberlândia - Campus Santa Mônica Bloco 1H, CEP: 38400-902, Uberlândia (MG), Brasil, Tel.: (+55 34) 32394381 - carlosrbrandao@yahoo.com.br

(2) Doutoranda no Programa de Pós-Graduação em Geografia da Universidade Federal de Uberlândia - Campus Santa Mônica - Bloco 1H, CEP: 38400-902, Uberlândia (MG), Brasil, Tel.: (+55 34) 32394381 - ale.leal@msn.com

\section{aaCaa}

Revista da ANPEGE, v. 8, n. 9, p. 73-91, jan./jul. 2012.

ISSN 1679-768 X @ $\odot 2003$, Associação Nacional de Pesquisa e Pós-Graduação em Geografia. Todos os direitos reservados. 


\section{INTRODUÇÃO}

Uma maneira pouco usual de se pensar a comunidade tradicional poderia revelar agora a sua utilidade. Ao invés de descrevermos com ênfase as estruturas sociais e alguns padrões internos de culturas das comunidades tradicionais, e as suas relações de sujeição diante de poderes externos ou, simplesmente, "da cidade", porque não ouvirmos o que nos dizem os seus sujeitos, suas mulheres e seus homens, seus sabres sobre si mesmos, seus imaginários e as suas memórias? Porque não deixarmos também a eles o trabalho de traduzirem para eles e para nós aquilo que acreditam ser o lugar onde vivem, o território que habitam, o modo de vida que constituem, a experiência de cultura que criam e em que se enredam, com variados graus de autonomia?

Se tomarmos uma linha de tempo arcaica o bastante em termos de história da região, podemos ousar como um ponto de partida a idéia de que, por oposição a todas as outras, são comunidades tradicionais aquelas que "ali estavam" quando outros grupos humanos, populares ou não, "ali chegaram" e ali se estabeleceram. Alargando uma vez mais o nosso compasso do olhar, podemos pensar que entre as tribos, comunidades tribais, aldeias indígenas, comunidades quilombolas, comunidades de camponeses tradicionais - entre povoadores esparsos nas antigas grandes fazendas, como "agregados" e/ou "moradores", a sitiantes tradicionais concentrados em bairros rurais ou em povoados - a levas de migrantes em "colocações" de seringueiros, a pequenas e até a pouco quase desconhecidas aldeias de pescadores artesanais de praias que depressa os guias de turismo descobrem hoje, todas estas categorias de "povoadores" indígenas e/ou tradicionais enquadram-se em uma das seguintes categorias, de acordo com a história ou a memória do tempo em que "estão e vivem ali":

a) São herdeiras de povoadores ancestrais, distantes da atual geração o bastante para que seus nomes, suas datas e seus feitos estejam totalmente apagados de registros históricos e/ou sejam revividos na memória como uma saga fundadora ou um pequeno repertório de mitos;

b) São herdeiras de povoadores ancestrais reconhecidos, de tal maneira que os dados de origem da geração fundadora estão estabelecidos como registro (não raro documentos pessoais ou cartoriais de fundação de lugar ou doação de terras) e cuja linha de sucessão de modo geral pode ser traçada até a presente geração;

c) A geração atual é ou se reconhece, desde um tempo passado, mas ainda presente na vida dos mais velhos ou na memória ativa de seus filhos, como fundadora original do lugar em que vive e da comunidade que constitui;

d) Uma leva de povoadores chega a um lugar e estabelece ali, em termos de uma "atualidade presente" uma comunidade com características culturais e identitárias que a aproximam de comunidades tradicionais mais antigas ou mesmo ancestrais. Muda-se, neste caso, um lugar atual de vida, mas não um modo antecedente de vida.

Em algum momento - ancestral, antigo, recente ou presente - uma comunidade tradicional existiu ou convive ainda com uma situação de fronteira. Em algum momento os seus primitivos, primeiros ou atuais povoadores chegaram "ali". Eis possivelmente um dos motivos pelos quais parecem ser raros os mitos ou as sagas em que um "povo" nasce pronto em um lugar, como no caso de povos indígenas, quando deuses ou seres naturais desde um lugar distante ou próximo geram seres humanos ancestrais e fundam "ali" um lugar social.

Logo nas primeiras linhas do capítulo mais teórico de seu livro Fronteira - a degradação do outro nos confins do humano, José de Souza Martins convoca um outro autor para lembrar que, de um modo ou de outro, a América Latina ainda envolve territórios, populações e sociedades em "estágio de fronteira". 
Com razão, observa Alistair Hennessy, que as sociedades latino-americanas ainda estão no estágio da fronteira. Ainda se encontram naquele estágio de sua história em que as relações sociais e políticas estão, de certo modo, marcadas pelo movimento de expansão demográfica sobre terras "não ocupadas" ou "insuficientemente" ocupadas (MARTINS, 1997. p. 132).

No mesmo parágrafo Martins afirma que "Na América Latina última grande fronteira é a Amazônia, em particular, a Amazônia brasileira" (MARTINS, 1997. p. 132). O que não significa que não existam, sobretudo aqui no Brasil, outras fronteiras: mais ativas no passado, e talvez menos hoje. Mas ainda vigentes de um modo ou de outro.

Para além do que caracteriza a fronteira desde um ponto geográfico, ecológico, demográfico, econômico ou político (inclusive no que se refere a políticas governamentais de "expansão de fronteiras" ou de "ocupação de territórios"), ela é o lugar social e simbólico da alteridade. É o lugar onde absolutos outros se encontram: o índio e o branco, o "selvagem" e o "civilizado", o conquistador e o conquistado, o colonizador e o colonizado, o pioneiro e o nativo, o rico e o pobre, o contemporâneo e o atrasado, "moderno" e o "tradicional".

Em síntese, aquele que desde muito ou algum tempo "ali" estava e vivia versus aquele que chegou a um suposto lugar natural vazio, desocupado, desabitado, ou povoado por povoadores autóctones que respondem justamente pelo ainda domínio da natureza sobre a cultura. Aquele que veio de longe para ocupar, para conquistar e colonizar algum "imenso vazio" e trazer para ali o desenvolvimento, o progresso, o domínio do homem sobre a natureza. Enfim fazer chegar ali a "civilização".

Um estado de fronteira não se dissolve quando mudanças demográficas e político-econômicas chegam a um estágio de realização consolidada. Ele se dissolve quando este "lugar de alteridade" torna-se não propriamente uniforme, mas uniformizado de acordo com novos poderes, leis e normas de relações com a natureza e entre pessoas e grupos de pessoas. Dissolve-se quando o "outro", aquele que foi encontrado no caminho do "estranho" (ou mesmo do estrangeiro) torna-se não como ele (o chegante), pois é justamente isto o que a maioria dos que vieram e chegaram não desejam, mas um algum dissolvido sob as e, somente assim, reconhecido pelas novas identidades do lugar. A ponto de poder-se dizer que um território de desigualdade e conflito entre alteridades como uma fronteira, resolveu-se em um região de submissão e consenso forçado, como um lugar afinal descoberto, civilizado, integrado.

A fronteira só deixa de existir quando o conflito desaparece, quando os tempos se fundem, quando a alteridade original e mortal dá lugar à alteridade política, quando o outro se torna parte antagônica do nós. Quando a história passa a ser a nossa história, a história de nossa diversidade e pluralidade, e nós já não somos nós mesmos porque somos antropofagicamente nós e o outro que devoramos e que nos devorou (MARTINS, 1997. p. 134).

Qual "outro"? Aquele que se tornou ele próprio um estranho diante da chegada de quem "veio de longe" e "tomou posse". "Apossear" seria a palavra com que em diferentes regiões do país é chamado este ato de conquista realizada tanto pelos pobres de antes e suas famílias, quanto pelos agentes do poder e do capital e seus emissários, antes e agora. Aquele que justamente por ser o "nativo", indígena, mestiço ou branco, confunde-se com a própria natureza. Aquele que aos olhos do "pioneiro" é visto como um alguém individual e coletivamente destinado a ser destruído ou dominado e tornado servil, cercado em terras de sobra, ou empurrado para uma outra região que em algum dia repetirá o mesmo destino de vir a ser... fronteira.

Martins lembra com acerto que quase sempre, mesmo nos estudos científicos a fronteira é percebida e descrita desde o ponto de vista do "que veio", "de quem chega lá". É desde o heróico pioneiro ou o inevitável colonizador (a vontade de Deus incluída) que a fronteira torna-se um lugar digno também de estudos sociais. Como se também para nós o território de fronteira fosse 
primeiro apenas um campo de interesse para o cientista da natureza, dos herboristas do passado aos ecólogos de hoje.

\section{DESENVOLVIMENTO - CRIAR}

No entanto, uma compreensão do que é um território que a chegada do "outro" torna uma fronteira, deveria ser realizada desde o lugar de quem "estava aqui" quando o "de fora" chegou. $\mathrm{Ou}$, se o que constrói o lugar-fronteira é a relação que o contato ou os encontros e desencontros entre quem "estava" e quem "chegou", então pelo menos tal relação deveria ser percebida e descrita como um acontecer entre duas-múltiplas categorias de sujeitos-atores. E não como algo que somente acontece a partir de quando um ator ativo domina um sujeito-objeto passivo e constrói sobre os termos deste domínio - que pretende ser também o de uma suposta natureza intocada uma história a ser narrada e uma sociedade a ser compreendida. Toda a fronteira é também algo como uma estrada de dupla-mão. Uma estrada-espelho do que a chegada do estranho provoca não raras vezes. Pois enquanto por um dos rumos chegam os que podem, pelo outro começam a sair e a migrar os que partem.

E esta compreensão abarca todo o lado da "vítima", ocasional ou propositadamente esquecido ou tornado opaco. Fronteiras que provocam o contato entre significações divergentes de tempoespaço, formas de apropriação de espaços naturais ou já socializados por algum tipo de trabalho antecedente, projetos de vida e de destinos diferentes, não podem deixar de abrigar o "acontecer do presente" (para retornarmos ao Heidegger de nossas primeiras páginas) sob a forma de práticas de ilegitimação o outro; de expropriação de pessoas, famílias e comunidades, de violência tornada institucional por quem "acaba de chegar" contra quem "já estava ali". E, justamente porque "chegou antes de nós", é uma presença que precisa ser carimbada de antemão como a daquilo ou daqueles que devem mudar o seu existir devido á chegada de quem, de um momento em diante, legitima o ato de estabelecer, de um lado e do outro da fronteira, como se deve ser, pensar e viver. Não é por outro motivo que desde tempos imemoriais, o pioneiro é também o conquistador de terras, bichos e gentes, antes de ser o colonizador de um território.

As concepções centradas na figura imaginária do pioneiro deixam de lado o essencial, o aspecto trágico da fronteira, que se expressa na mortal conflitividade que a caracteriza, no desencontro genocida de etnias e no radical conflito de classes sociais contrapostas não apenas pela divergência de seus interesses econômicos, mas sobretudo pelo abismo histórico que as separa. Na fronteira o camponês ainda vive relações econômicas, concepções de mundo e devida centradas na família e na comunidade rural, que persistem adaptadas e atualizadas desde tempos pré-capitalistas. Ele, que ainda está mergulhado na realidade de relações sociais que sobrevivem do período colonial, se descobre confrontado com formas tecnologicamente avançadas de atividade econômica, do mundo, do satélite, do computador, da alta tecnologia. E subjugado por formas de poder e de justiça que se pautam por códigos e interesses completamente distanciados de sua realidade aparentemente simples, que mesclam diabolicamente o poder pessoal do latifundiário e as formas puramente rituais de justiça institucional. (MARTINS, 1997. p. 13.)

Teremos nós próprios, habitantes das fronteiras da academia com o mundo, adotado do próprio colonizador uma das formas de "ver a fronteira"? José de Souza Martins lembra uma oposição que poderia sugerir isto.

$\mathrm{Na}$ tradição pelo menos brasileira, uma primeira geografia acentuou no processo de expansão de territórios a frente pioneira. Sua direção era do lugar civilizado para o selvagem, ou o atrasado; da cidade para o campo e do campo para o ermo, a floresta. Do atraso para o progresso. Seu sujeito, o pioneiro, qualquer que seja em cada caso o seu nome. Os outros, os que "lá estavam", confundiamse, como vimos antes, com as paisagens de uma natureza a ser, com todos os seus espaços naturais 
e os seus seres vivos, desbravada, conquistada e incorporada ao mundo social de quem veio "de lá até aqui”. (MARTINS, 1997. p. 134.)

Em um momento posterior, uma antropologia em que destaca a pessoa de Darcy Ribeiro em seus primeiros estudos, aprende a olhar o território da fronteira e o acontecer dos processos sociais que a transformam - justamente - em uma "fronteira", desde o ponto de vista de quem foi para lá antes, como uma frente de expansão, antes da chegada da frente pioneira, ou bem antes da chegada de ambas. Assim, sob o olhar desta outra antropologia, o que passa a interessar não é mais "o que se transforma com a chegada do pioneiro", mas em como a sua chegada imposta ao outro "afeta a vida de lá estava". Importante o fato de que este olhar sobre a fronteira desde o ponto de vista da frente de expansão totaliza aquilo que o olhar colocado sobre a frente pioneira não consegue ver por inteiro.

Em primeiro lugar porque o olhar da antropologia totaliza o acontecer da fronteira. Procura compreender como um complexo sistema de contato, encontros e desencontros o que passa a ocorrer em um lugar de diferentes culturas inserido em uma mesma natureza. Em segundo lugar porque totaliza a própria "frente". Ela deixa de ser o movimento de expansão do herói-pioneiro e passa a ser um movimento múltiplo, ocorrendo em e entre diferentes tempos-espaços. Envolvendo diversos atores sociais, entre ricos e pobres, entre expropriadores e expropriados, entre emissários do capital e do poder e os subalternos diretos ou indiretos à novidade perversa da chegada de um e do outro. Falando de Darcy Ribeiro eis o que lembra Martins.

Esse antropólogo não vê a frente de expansão como sendo apenas o deslocamento de agricultores empreendedores, comerciantes, cidades, instituições políticas e jurídicas. Ele inclui nessa definição também as populações pobres, rotineiras, não indígenas ou mestiças, como os garimpeiros, os vaqueiros, os seringueiros, castanheiros, pequenos agricultores que praticam uma agricultura de roça antiquada e no limite do mercado (MARTINS, 1997. p. 135.).

Em uma outra situação que não esta seria um excelente exercício o colocarmos em paralelo as idéias de Zygmunt Bauman, as de Michel Maffesoli, e as de Homni Bhabha a respeito da presença marcada, desejada e contraditória da comunidade em nosso mundo de agora. De modo diferente, no entanto, devemos nos reaproximar da comunidade tradicional através de um outro confronto. Ele será entre Homni Bhabha e Manuela Carneiro da Cunha. Outros pesquisadores de campo serão convidados adiante.

A que se opõe a comunidade? Ao que tenta revertê-la à sociedade e, da sociedade, ao mercado globalizado. De maneira não muito distante de Maffezoli e Bauman, a comunidade é o lugar humano da vida. Desde tempos antigos foi e segue sendo o lugar social arrancado da natureza, ou nela encravado ainda, em que pessoas, famílias e redes de parentes e "comuneiros" reúnem-se para viver suas vidas e dar, entre palavras e gestos, um sentido a ela. Em termos modernos, a comunidade é o lugar da escolha. É a associação, quanto mais livre e auto-assumida melhor - de pessoas que se congregam para serem, em meio a um mundo como o da grande cidade, o que desejam ser nela, ou por oposição a ela.

Reportando-se a Partha Chatterjee, um outro indiano, Bhabha sugere que a idéia de comunidade:

... articula uma temporalidade cultural de contingência e indeterminação no cerne do discurso da sociedade civil. Essa leitura "minoritária" construída sobre a presença ocluída, parcial de uma idéia de comunidade que ronda ou duplica o conceito de sociedade civil. Levando a 'uma vida subterrânea, potencialmente subversiva no seu interior, porque se recusa a "ir-se".

A comunidade perturba a grande narrativa globalizadora do capital, desloca a ênfase dada à produção na coletividade "de classe" e rompe a homogeneidade da comunidade imagina da nação. (BHABHA, 1998. p. 316) 
Que não pareça ao leitor uma ousadia demasiada a nossa intenção de estender o argumento de Bhabha a pelo menos quatro situações às quais se aplica o conceito comunidade:

a) A comunidade primitiva (mais no sentido de autóctone do que no de "selvagem") em algum momento confrontada com uma sociedade colonial e colonizadora;

b) A comunidade tradicional típica, nos termos em que buscamos aqui compreendê-la, e que a partir de um momento dado como um "acontecer presente" imposto torna-se o lugar dos pobres, dos expropriáveis, dos resistentes, em uma situação de fronteira;

c) A comunidade de exclusão em geral formada por desalojados-e-migrantes pobres, habitante coletiva grande cidade e, de modo geral, escanteada para alguma de suas terras de sobra;

d) A comunidade de adesão constituída como unidade, agrupamento ou rede de pessoas que se reúnem por escolha mútua para criarem uma unidade de ação social, não raro sob a forma de alguma cultura de fé, margem e protesto.

Em qualquer uma de suas dimensões, e por diversas que elas possam ser, a comunidade é a paráfrase do lugar-humano. É aquilo que se cria em um espaço-de-vida quando ali se vive, quando ali se chega ou quando para ali se vai de maneira imposta e arbitrária. Um campo de refugiados é inicialmente um aglomerado de desalojados. O que em pouco tempo se cria endogenamente ali é uma comunidade ou são algumas comunidades. Anterior, contemporânea ou posterior à "chegada do estranho", a comunidade é o como se pode fazer frente ao capital, ao poder exterior, ao mercado, à sociedade de massa e mídia.

78 Não por ser patrimonialmente uma guardiã do passado, ou por ser expressivamente "folclórica", "típica" ou um "genuíno exemplo de nossas mais preciosas tradições", uma comunidade popular (mas nem todas) é também tradicional. Ela o é por representar uma forma ativa e presente de resistência à quebra de um reduto inter-humano de relações ainda centradas mais em pessoas e redes de reciprocidade de/entre sujeitos-atores através de produto do trabalho, do que em coisas e trocas de mercadorias através de pessoas, tornadas elas próprias, seres-objeto.

A comunidade é o suplemento antagônico da modernidade: no espaço metropolitano ela é o território da minoria, colocando em perigo as exigências da civilidade; no mundo transnacional ela se torna o problema de fronteira dos diaspóricos, dos migrantes, dos refugiados. (BHABHA, 1998. p. 317)

Observemos que sendo por exclusão ou eleição algo que se refere, sobretudo em contextos como os latino-americanos, às "imensas maiorias" dos pobres e postos à margem, uma comunidade, para ser o que é, configura-se sempre como uma unidade mínima - por isso aparentemente minoritária - dessa maioria. Por isso também é que mesmo antes de nos pensarmos como uma "aldeia global", a realidade das pequenas comunidades populares está tanto na peculiaridade de presença e vida social de cada uma delas, como na teia, visível ou não aos "de fora", de iguais unidades tradicionais de vida e trabalho, que torna possível - tanto ou mais do que a cidade e o mercado - a existência de cada uma.

Algo talvez inesperado ocorra hoje no universo das comunidades que vão de uma aldeia, ou um conjunto de aldeias indignas, a colocações de seringueiros e a unidades de moradia de coletadores de castanhas ou de quebradeiras de coco.

Embora, como buscaremos mostrar, as populações tradicionais tenham tomado os povos indígenas como modelos, a categoria "populações tradicionais" não os inclui. A separação repousa sobre uma distinção legal fundamental: os direitos territoriais indígenas não têm como fundamento a conservação ambiental, mesmo quando se verifica que terras indígenas figuram como "ilhas" de conservação em contextos de acelerada devastação. Para realçar essa especificidade da legislação brasileira que separa 
os povos indígenas das "populações tradicionais", não os incluiremos nesta categoria, e usaremos, quando necessário, a expressão "populações indígenas e tradicionais". (CUNHA, 2009. p.219).

Em alguns anos, e sem que o essencial do que os ameaça cotidianamente em regiões de fronteira e de cobiça das frentes do capital tenha se reduzido, tais comunidades em termos de militância de resistência, de presença política e jurídica e de imagens na mídia passaram de "entrave ao progresso" a coletividades abrangidas pelos direitos humanos. As unidades sociais credoras de dívidas históricas, a aliadas do meio-ambiente, logo, a atores pessoais (como Chico Mendes) ou coletivos de importância pelo menos em textos e decretos de políticas públicas. Tanto é assim que existe no IBAMA o Centro Nacional de Populações Tradicionais. Ver no livro "Cultura com Aspas" de Manuela Carneiro da Cunha, na página 278.

De dentro da floresta, em algum lugar fora dos roteiros de asfalto do sertão, povo, populações, comunidades tradicionais se fazem ouvir em um triplo sentido:

a) Unem-se para proclamar seus direitos e cobrar do poder público e de ONGs promessas e parcerias, inclusive as que se referem a salvaguardas que vão desde territórios patrimoniais até "patrimônios culturais imateriais";

b) Inserem-se de maneira em alguns casos inovadora e rentável em regiões econômicas menos periféricas do mercado de bens, sobretudo no que se refere a produtos de coleta da natureza;

c) Redefinem-se como agentes de sustentabilidade anteriores às política públicas dirigidas à salvaguarda do meio ambiente.

O que este cenário deixa de reconhecer é que a situação mudou, e com ela a validade dos antigos paradigmas. As populações tradicionais não estão mais fora da economia central, nem mais simplesmente na periferia do sistema mundial. As populações tradicionais e suas organizações não tratam apenas com fazendeiros, madeireiros, garimpeiros. Elas tornaram-se parceiras de instituições centrais como as Nações Unidas, o Banco Mundial e as poderosas ONGs do "primeiro mundo" (CUNHA, 2009. p. 289).

Por otimista que possa parecer, esta passagem revela um evidente - embora ainda muito limitado - novo "acontecer do presente" ao redor das comunidades indígenas e comunidades tradicionais, sobretudo em regiões críticas de fronteira e de expansão expropriadora do agronegócio.

Em outra direção, passando do estigma identitário imposto "pelos que chegam", pessoas e grupos humanos indígenas, mestiços, quilombolas, habitantes de terras de sobra, reapresentam-se como senhores de direitos ancestrais. Direitos agora tornados legítimos justamente por haverem sido antes aquilo que os desqualificava no passado: o serem índios, negros, mestiços, pobres e marginalizados.

Olhada desde o lugar de onde chegam os que vêm para comercializar produtos e/serviços com ela, para expropriá-la, para convocá-la 'a mudança e ao progresso, para convertê-la a um outro deus ou a um outro modo de pensar o mesmo deus, ou simplesmente para compreendê-la e escrever sobre ela, a comunidade tradicional, sua cultura, seu modo de vida, suas pessoas, foram e seguem sendo o que a cada momento da história se enuncia a seu respeito. Resquício do passado "de nossas culturas mais autênticas" a ser "preservado"; produtora da maior parte dos bens-de-mesa de nossas refeições diárias; "lugar do atraso e entrave ao progresso" e, mais recentemente, exemplo de harmonia com a natureza e de desenvolvimento sustentável.

Com acerto Manuela Carneiro da Cunha desconfia de formas usuais de qualificação das tão diversas populações tradicionais.

O emprego do termo "populações tradicionais" é propositadamente abrangente. Contudo, esta abrangência não deve ser tomada por confusão conceitual.

Definir as populações tradicionais pela adesão à tradição seria contraditório com os conhecimentos 
antropológicos atuais. Defini-las como populações que têm baixo impacto sobre o ambiente, para depois afirmar que são ecologicamente sustentáveis, seria mera tautologia. Se as definirmos como populações que estão fora da esfera do mercado, será difícil encontra-las hoje em dia.

Por enquanto, achamos melhor definir as "populações tradicionais" de maneira "extensional", isto é, enumerando os seus "membros" atuais, ou candidatos a "membros". Essa abordagem está de acordo com a ênfase que daremos à criação e à apropriação de categorias, e, o que é mais importante, ela aponta para a formação de sujeitos por meio de novas práticas . (CUNHA, 2009. p. 278).

Esta maneira de "ver o outro" entre a unidade do que é partilhado e as diferenças que tornam a própria partilha de qualificadores comuns possível, tem sido usual não apenas entre antropólogos. Assim, ao lado de se reconhecer que em algum lugar e de alguma aceitável e discutível maneira deve haver uma "cultura popular", no Norte de Minas, por exemplo, com freqüência preferimos empregar termos como: cultura sertaneja, cultura vazanteira, cultura camponesa, cultura nortemineira, cultura quilombola, e, entre os mais afoitos: culturas híbridas.

Diante da dificuldade de encontrar um consenso sobre o que venha a ser o "tradicional", depois que ele é separado do primitivo, indígena, tribal, talvez o melhor procedimento seja pluralizar o seu âmbito e centrar características diferenciadoras sobre cada formação social que, de algum modo, tenha algo em comum com o que está, justamente, entre o indígena e o urbano (moderno, desenvolvido, capitalista, etc.).

Um dos antropólogos que mais têm trabalhado a questão das novas territorializações e das terras de etnia (indígenas e quilombolas) e do que chamo aqui de terras de sobra (de que o fundo de pasto é um bom exemplo) é Alfredo Wagner Berto de Almeida. Longa demais que seja, uma contribuição sua deve ser colocada aqui. Ele trata com mais detalhes do caso da Amazônia.

Há, portanto, diferentes processos de territorialização em curso que devem ser objeto de reflexão detida. Babaçuais, castanhais e seringais, sob este prisma, não significam apenas incidência de uma espécie vegetal ou uma "mancha", como se diz cartograficamente,mas tem uma expressão identitária traduzida por extensões territoriais de pertencimento. Esta expressão foi construída politicamente através das mobilizações por livre acesso aos recursos básicos. Para se ter uma ordem de grandeza destas territorialidades especificas, que não podem ser lidas como "isoladas" ou "incidentais", podese afirmar o seguinte: dos 850 milhões de hectares no Brasil cerca de 1/4 não se coadunam com as categoria: estabelecimento e imóvel rural e assim se distribuem: cerca de $12 \%$ da superfície brasileira, ou aproximadamente 110 milhões de hectares, correspondem a cerca de 600 terras indígenas. Estima-se oficialmente que as terras de quilombo correspondam a mais de 30 milhões de hectares. Em contraste, as terras de quilombos tituladas correspondem a cerca de 900 mil hectares. Os babaçuais sobre os quais as quebradeiras começam a estender as Lei do Babaçu Livre correspondem a pouco mais de 18 milhões de hectares, localizados notadamente no Meio-Norte. Em contrapartida as reservas extrativistas de babaçu não ultrapassam 37 mil hectares. Os seringais se distribuem por mais de 10 milhões de hectares e são objeto de diferentes formas de uso. Embora o Polígono dos Castanhais, no Pará, tenha um milhão e duzentos mil hectares, sabe-se que há castanhais em Rondônia, no Amazonas e no Acre numa extensão não inferior a 15 milhões de hectares. Em contrapartida as reservas extrativistas de castanha, de "seringa" e de pesca perfazem menos de $10 \%$ do total das áreas com incidência de extrativismos, ou seja, um total de 3.101 .591 hectares, com população de 36.850 habitantes.

Acrescentando-se a estas extensões aquelas dos extrativistas do açaí, do arumã, dos ribeirinhos e das associações de fundo de pasto (na região do semi-árido) e demais povos e grupos sociais que utilizam os recursos naturais sob a forma de uso comum, numa rede de relações sociais complexas, que pressupõem cooperação simples no processo produtivo e nos afazeres da vida cotidiana, tem-se um processo de territorialização que redesenha a superfície brasileira e lhe empresta outros conteúdos sociais condizentes com as novas maneiras segundo as quais se organizam e autodefinem os sujeitos sociais. $28 \mathrm{Em}$ verdade o que ocorre é a construção de identidades específicas junto com a construção de territórios específicos. O advento de categorias como os chamados "sem-terra" e os "índios misturados"29 também podem 
permitir um entendimento mais acurado deste processo. Anote-se que novos povos indígenas estão surgindo, tanto na Amazônia, quanto no Nordeste ou no Sudeste do País.

Veja-se o exemplo do Ceará que vinte anos atrás oficialmente não registrava índios e hoje possui nove ou dez povos indígenas. Concomitante ao "surgimento" há critérios político- organizativos que se estruturam em cima da demanda por terras. As terras vão sendo incorporadas segundo uma idéia de rede de relações sociais cada vez mais fortalecida pelas autodefinições sucessivas ou pela afirmação étnica. Para bem ilustrar isto recorra-se à leitura dos dados censitários: o Censo Demográfico de 2000 constata que os povos reunidos sob a classificação de indígenas foram os que tiveram a maior taxa de crescimento populacional entre 1991 e 2000. Cresceram a uma taxa anual de 10,8\%, duplicando sua participação no total da população brasileira de $0,32 \%$ para $0,4 \%$. Sublinhe-se que neste mesmo período a população total do Brasil cresceu a uma taxa de $1,6 \%$ ao ano. Os que se autodeclararam pretos30 aumentaram $4,2 \%$. O crescimento de indígenas e de pretos não se deveu à multiplicação da população de aldeias e comunidades negras, mas a uma mudança na maneira de auto-identificação do recenseado.

Sim, as pessoas estão se autodenominando na relação das identidades de afirmação étnica, que pressupõem territorialidades específicas. Elegendo a região Norte, Amazônia, constatamos que apenas $29,3 \%$ se autodenominam brancos, todos os demais, ou seja, mais de $2 / 3$ da população, se apresentam como indígenas, pretos e pardos. Em outras palavras a região Norte tem uma "fisionomia étnica" que aparentemente, pelo percentual dos brancos, mais poderia ser aproximada de países como Bolívia, Peru e Equador. Assim, juntamente com o processo de territorialização tem-se a construção de uma nova "fisionomia étnica", através da autodefinição do recenseado, e de um redesenho da sociedade que lhes possam permitir uma compreensão mais precisa das modalidades de uso comum vigentes. Definir oficialmente unidades de conservação apenas pela incidência de espécies31 e operar com as categorias cadastrais e censitárias convencionais significa incorrer no equívoco de reduzir a questão ambiental a uma ação sem sujeito. Os movimentos sociais apresentam-se como um fator de existência coletiva que contesta esta insistência nos procedimentos operativos de ação sem sujeito. É deste prisma que pretendo chamar a atenção para a relevância de se abrir uma discussão ampla sobre as "terras tradicionalmente ocupadas" e sobre os processos de territorialização que lhes são correspondentes no momento atual. (ALMEIDA, 2004. p. 28)

Algumas linhas acima vimos Manuela Carneiro da Cunha empregando a mesma categoria de Alfredo Wagner: populações tradicionais. Como, mais do que "populações", em um sentido demográfico do termo, elas são e se representam como coletividades reunidas em diferentes modalidades de comunidades, acreditamos que a expressão comunidades tradicionais as qualifica de forma mais adequada.

Mas a lembrança de Manuela vale aqui pelo fato de que acentua algo tão sabido quando esquecido. Populações ou comunidades tradicionais não são mais folclóricos agrupamentos humanos encerrados nos confins da floresta ou esquecidos nos ermos dos sertões. São também unidades culturais conectadas com o mundo. Participam das mesas redondas dos congressos científicos desde onde nos desafiam. Conversam com agentes do Banco Mundial e, bem sabemos, um brado de um chefe indígena lúcido e irado pode repercutir nas Nações Unidas bem mais do que os relatórios de nossas pesquisas.

Alfredo Wagner trás aqui o outro lado desta evidência. Territórios tradicionalmente ocupados não são uma pitoresca exceção. Não são sobras do passado, e não são uma demografia, uma antropologia, uma história e uma geografia do pitoresco a desprezar em estudos sérios. Ao contrário, juntamente com as comunidades indígenas elas representam hoje uma quantidade de territórios e uma qualidade de diferentes modos de vida e de culturas que poderiam nos obrigar a uma revisão de nossas idéias - inclusive constitucionais - de etnicidade e de territorialidade.

Sigamos em frente. Em um trabalho coordenado por Antônio Carlos Diegues e Rinaldo S. V. Arruda e editado pelo Ministério do Meio Ambiente, há um denso esforço em caracterizar saberes, populações ou comunidades tradicionais (DIEGUES, 2001). Em seu estudo em que a ênfase recai 
sobre a relação tradicionalidade, sustentabilidade, biodiversidade, os autores elencam características do que seriam sociedades, populações ou comunidades tradicionais que, a nosso ver, fazem avançar bastante as concepções anteriores. Visões do outro que sobretudo nos tempos dos primeiros estudos de comunidade percebiam e descreviam de forma estática e estratigráfica tais comunidades .

Saibamos acompanhar por um momento a longa listagem de indicadores das sociedades tradicionais, em Diegues e Arruda.

Com base nas considerações anteriores, pode-se dizer que essas sociedades se caracterizam:

. pela dependência da relação de simbiose entre a natureza, os ciclos e os recursos naturais com os quais se constrói um modo de vida;

. pelo conhecimento aprofundado da natureza e de seus ciclos, que se reflete na elaboração de estratégias de uso e de manejo dos recursos naturais. Esse conhecimento é transferido por oralidade de geração em geração;

. pela noção de território ou espaço onde o grupo social se reproduz econômica e socialmente;

- pela moradia e ocupação do território por várias gerações, ainda que alguns membros possam ter-se deslocado para os centros urbanos e voltado para a terra de seus antepassados;

- pela importância das atividades de subsistência, ainda que a produção de mercadorias possa ser mais ou menos desenvolvida, o que implicaria uma relação com o mercado;

. pela reduzida acumulação de capital;

- pela importância dada à unidade familiar, doméstica ou comunal e às relações de parentesco e compadrio para o exercício das atividades econômicas, sociais e culturais;

. pela importância das simbologias, mitos e rituais associados à caça, pesca e atividades extrativistas; - pela tecnologia utilizada, que é relativamente simples, de impacto limitado sobre o meio ambiente; há uma reduzida divisão técnica e social do trabalho, sobressaindo o artesanal, cujo produtor e sua família dominam todo o processo até o produto final;

- pelo fraco poder político, que em geral reside nos grupos de poder dos centros urbanos; e

. pela auto-identificação ou identificação por outros de pertencer a uma cultura distinta. (DIEGUES, 2001. p. 59).

Com um outro olhar, bastante próximo ao de boa parte dos novos estudos de comunidades primitivas e/ou tradicionais, nossos autores deslocam o eixo de uma tradicionalidade cultural centrada sobre a interioridade peculiar de um modo de vida, para questões que priorizam a questão da ocupação ancestral ou recente de um território. Para o manejo do meio ambiente, para as formas patrimoniais de saberes e práticas de tal manejo, para a organização interna das unidades comunitária e sua dependência, sobretudo política e econômica frente aos centros urbanos próximos em mais remotos e, mais ainda, a dimensão identitária alter ou auto atribuída.

Em um momento posterior do mesmo livro, Diegues e Arruda chegam a uma síntese em que por uma questão irão divergir de Manuela Carneiro da Cunha.

Assim, utiliza-se neste estudo a noção de sociedades tradicionais para definir grupos humanos diferenciados sob o ponto de vista cultural, que reproduzem historicamente seu modo de vida, de forma mais ou menos isolada, com base na cooperação social e relações próprias com a natureza. Essa noção refere-se tanto a povos indígenas quanto a segmentos da população nacional, que desenvolveram modos particulares de existência, adaptados a nichos ecológicos específicos.

Exemplos empíricos de populações tradicionais são as comunidades caiçaras, os sitiantes e roceiros, comunidades quilombolas, comunidades ribeirinhas, os pescadores artesanais, os grupos extrativistas e indígenas. Exemplos empíricos de populações não-tradicionais são os fazendeiros, veranistas, comerciantes, servidores públicos, empresários, empregados, donos de empresas de beneficiamento de palmito ou outros recursos e madeireiros (DIEGUES, 2001. p. 62).

Nesta proveitosa definição de síntese, Diegues e Arruda incluem as comunidades indígenas no círculo das comunidades tradicionais (o que não faremos aqui). De outra parte, ao procurarem 
seus opostos ou, pelo menos, os seus diferentes, eles elencam em maioria categorias de sujeitos individuais ou coletivos pertencentes ao pólo do poder e do capital. Em boa medida isto é verdadeiro e visivelmente atual, pois bem sabemos que os lugares de dependência e de oposição da pequena comunidade tradicional estão na cidade e na empresa. Estão entre políticos, banqueiros e empresários.

No entanto, em nome da própria absoluta atualidade desde onde falam, seria indispensável colocar no tabuleiro deste complexo jogo-rito de identidades e diferenças, outros sujeitos também presentes e, hoje, mais do que nunca. Vale acrescentar que em outro trabalho, Diegues afirma o seguinte.

O território das sociedades tradicionais, distinto das sociedades urbanas industriais, é descontínuo, marcado por vazios aparentes (terras em pousio, áreas de estuário que são usadas para a pesca somente em algumas estações do ano) e tem levado autoridades da conservação a declará-lo parte das unidades de conservação, porque não é usado por ninguém (DIEGUES, 2001. p. 84).

Assim sendo, podemos perguntar que lugar ocupariam categorias de pessoas, de famílias, de redes de parentesco, de neo-comunidades como as que ao longo das estradas semeiam "acampamentos de lona preta" dos movimentos sociais pela reforma agrária? E os desalojados de barragens ou de novas reservas biológicas e parques naturais? Ou ainda os que aqui e ali são beneficiados por novos projetos de assentamento e ocupação modernizada de terras de produção, como os "irrigantes" dos projetos ao longo de partes do rio São Francisco?

A seu lado poderiam sem grandes problemas serem colocadas as unidades sociais de produção agropastoril (bem mais agro do que pastoril) das recentes experiências comunitárias de formação de núcleos de agrovilas, de agricultura orgânica, de permacultura, e outras variáveis. Esta é uma questão a que retornaremos adiante.

Da relação de indicadores do "tradicional" em uma comunidade "relativamente isolada", cremos que ficou de fora (e não por esquecimento, pelo que conhecemos de seus autores) alguns qualificadores importantes que nos remetem a José de Souza Martins e, com ele, nos convidam a outros estudiosos da questão rural no Brasil de hoje.

Talvez o cenário descrito por Diegues e Arruda seja o mais completo dentre os que procuram de algum modo caracterizar a comunidade tradicional e seus derivados. Entretanto, seria oportuno reforçar alguns qualificadores e acrescentar outros, cujo valor é tão relevante quanto os listados acima. Quais seriam eles?

A transformação da natureza: mais do o existir em um território achado, doado, conquistado, apropriado e tido como um lugar natural e social legítimo de existência de uma comunidade de ocupação, o que qualifica uma comunidade tradicional é o fato de que ela se tornou legítima através de um trabalho coletivo de socialização da natureza. Um trabalho sem interrupções realizado ao longo de gerações ou, no limite, através da geração presente. Assim, um lugar natural - não raro lembrado como selvagem, intratável, vazio e doentio - que "não era assim", "ficou assim" através e ao longo de um múltiplo e complexo modo rústico de trabalho. Um trabalho associado a um saber peculiar que, com mínimos recursos econômicos, empresariais e tecnológicos, se comparados como os das neo-unidades do agronegócio, por exemplo, tornaram um espaço de natureza em um lugar social humanamente habitável e, em seus termos próprios, produtivo.

A autonomia: é preciso que uma pequena comunidade quilombola ou extrativista esteja muito isolada "do resto do mundo", para que não se reconheça relacionada e inter-dependente:

a) de outras comunidades com iguais características e, não raro, com uma mesma história de presença no lugar;

b) de outras comunidades maiores, onde (como nas gradações de João Guimarães Rosa) existe já um equipamento urbano e um "comercinho" que a coloca a meio caminho entre um aglomerado rural e uma cidade: 
c) com as cidades próximas e até mesmo mais distantes.

Este fato não invalida um outro, também evidente e igualmente reconhecido. O de que, se comparados com os "peões de fazenda", com os empregados de empresas rurais e com os trabalhadores assalariados da/na cidade, pessoas, famílias e unidades de vizinhança e trabalho das comunidades tradicionais realizam o seu trabalho e vivem suas vidas com graus de autonomia qualitativamente diferentes e bem maiores.

"Trabalhar no que é seu"; "ser dono do seu tempo de trabalho"; "ser livre (mesmo que em termos relativos) para decidir o destino de sua produção de bens da terra ou mesmo de artesanato. Enfim, "trabalhar sem patrão, mesmo que na lida do pobre" são qualificadores altamente valorizados de um modo de vida em que muitas vezes o preço de uma assumida "condição de pobre" é a experiência da autonomia, traduzida como uma espécie sempre desejada de liberdade: "ser dono do seu" e, por este meio, "ser dono de sua vida".

A autoctonia: não sabemos bem se esta palavra aparentemente ambígua seria a melhor aqui. Mas é a que talvez melhor traduza o descender e/ou saber-se e sentir-se descendente de uma geração ou de uma linhagem de uma pessoa, de algumas pessoas, de uma família original ou de um pequeno grupo de parentes ou parceiros fundadores. Reconhecer-se, portanto, como uma comunidade presente herdeira de nomes, tradições, lugares socializados, direitos de posse e proveito de um território ancestral, que pode vir de tempos imemoriais ("isso vem dos tempos de Adão") ou de tempos muito próximos, como aquele em que cabem a geração fundadora e a de seus filhos.

Este é um dos qualificadores lembrados por Diegues e Arruda. Será proveitoso fazê-lo integrarse com os anteriores, para lembrar que não é uma presença pura e simples em um lugar, entre ancestrais e contemporâneos o que garante direitos de posse e uso. É uma presença realizada através de um trabalho socializador da natureza e integrador de pessoas e teias sociais entre pessoas, através de gerações. É esta lembrança viva do que "os nossos fizeram aqui” o que torna uma memória de autoctonia um atestado de direitos, segundo os códigos e gramáticas de uma jurisprudência também tradicional que se acredita valer tanto quanto aquela reconhecida como "vinda de fora" e oficial: a "dos homens do poder".

A memória de lutas passadas de resistência: talvez este seja ao indicador de presença e memória de uma comunidade tradicional esquecido em Diegues e Arruda, e tão lembrado em outros autores, tais como José de Souza Martins, e cuja lembrança nos parece ser essencial.

De fato, são poucos os casos de comunidades tradicionais populares em que a memória dos fatos e feitos, das histórias e estórias da fundação do lugar e de sua continuidade não esteja associada a situações de luta e conquista, de confronto, expropriação e resistência. Em um primeiro contar de memória, algumas lembranças dos “mais velhos aqui do lugar" farão referência longínqua à presença de grupos e comunidades indígenas. Então não é raro que, de maneira sempre vaga e imprecisa, alguns fragmentos de uma história oral e mítica faça dos primeiros fundadores do lugar e das gerações de sucessores.

Mas será sempre sobre uma lembrança, não raro datada e situada, de lutas contra frentes expropriadoras do passado distante ou próximo, o que qualifica a própria autoctonia. A geração atual sucede em linha direta uma ou algumas gerações que não apenas chegaram "aqui", povoaram, socializaram e significaram "este lugar", mas também resistiram a passadas ou até mesmo a presentes e ativas situações de cercamento, de ameaça, de expropriação ou mesmo de conflito armado aberto.

Assim, em muitas situações presentes, uma comunidade tradicional não se reconhece como tal apenas por serem eles e os seus modos de vida "diferenciados do ponto de vista cultural", como grifamos na conceituação de Diegues e Arruda, mas, também, por haverem no correr dos tempos, criado, vivido e transformado padrões de cultura e modo de vida em que a luta, o sofrimento, a ameaça e a resistência estão no cerne da memória. 
Assim, são conhecidos casos de comunidades quilombolas cuja ancestral origem é atribuída a um gesto pacífico: a doação das terras a uma ou a algumas famílias de ex-escravos. Em outros casos o quilombo origina-se de uma ato de resistência: a fuga de escravos ou o abandono ostensivo de uma fazenda e a criação de um lugar de refúgio e luta. Em algumas situações depois de um tempo de paz devida ao próprio isolamento da comunidade original e de seus herdeiros, "vieram tempos em que chegaram eles", sujeitos de fazendas, empresas e negócios, que instauraram um tempo anterior e/ou presente de ameaças, expropriações, cercamentos e conflitos.

A história de lutas e resistências atuais: da memória de tempos passados e conflitos "com os homens" parcial ou totalmente resolvidos não são poucas as comunidades tradicionais em que esta memória do passado continua numa vivida história de presente. Pode mesmo acontecer de a geração atual reconhecer-se como aquela que assistiu a chegada dos "tempos da Besta Fera". Entre conflitos armados e lentos enfrentamentos jurídicos, boa parte do que configura o que culturalmente chamamos de um modo de vida, realiza-se também politicamente como um trabalho comunitário de resistência atual.

Em alguns casos drásticos, ameaças vindas de transformação de um lugar social de vida popular em um imenso espelho d'água de uma grande represa, o que provoca do deslocamento total ou parcial da comunidade para uma "nova área", quase sempre diversa e bastante pior do que a "lá de onde a gente vivia". A criação de espaços públicos e oficiais de salvaguarda de natureza e biodiversidade pode criar situações semelhantes, em que as reservas extrativistas surgem como um modelo promissor, mas quase sempre também de difícil conciliação.

Finalmente, as ameaças de expropriação ou de transformações rápidas e de efeito direto sob o modo de vida tradicional, provindas de frentes pioneiras, através das diferentes modalidades da expansão do capital sob a forma de fazendas-empresas de mono-produção de gado de corte, de vegetais de transformação (milho, cana) ou e exportação direta (soja). Ou sob a forma de empresas madeireiras ou mineradoras, de ação direta sobre biomas como a floresta ou o cerrado.

A experiência da vida em territórios cercados e ameaçados: a expulsão de toda uma comunidade de sua "terra de sempre" é uma forma radical de expropriação passada e presente. A redução progressiva do território original até limites não raro exíguos o bastante para não suportarem mais a demografia original de uma comunidade tradicional é outra. Não são poucas as comunidades tradicionais do Norte de Minas - para ficarmos em nossa geografia mais familiar - cercadas entre terras que se percorre a pé em poucos minutos, entre a margem de um rio e uma longa cerca de arame. Isto quando uma comunidade já não se constitui no que estamos chamando aqui de terras de sobra. Em altos de chapada, em fundos de pasto, em territórios até agora sem serventia para as frentes expropriadoras.

Um dos atributos nem sempre reconhecidos até mesmo por seus pesquisadores de campo, está em que a comunidade não se faz "tradicional" por meio de alguns traços folclorizáveis de sua cultura. Elas se tradicionalizam como uma estratégia de defesa. Como um modo de existir dividido entre a relação dependente dom o "mundo de fora" e uma protegida quase-invisibilidade. Índios, quilombolas, camponeses antes e agora vivendo sob o peso de contínuas ameaças, resistem procurando também fazerem-se invisíveis aos olhos do outro. Quase invisíveis, mas presentes.

E é sobre uma anterioridade vivida e pensada, sobre a afirmação de que "a gente já estava aqui quando eles chegaram, mesmo que eles não tenha visto a gente" (ou até por isto mesmo) que a comunidade tradicional reconstrói tanto a sua identidade quanto o fundamento dos seus direitos a permanecerem "aqui” e a se reproduzirem "como nós sempre fomos".

Assim sendo, elas não são tradicionais porque aos olhos de quem chega opõem-se ao que, segundo "eles" é: moderno. São tradicionais porque são ancestrais, porque são autóctones, porque são antigos, resistentes anteriores. Porque possuem uma tradição de memória de si mesmos em nome de uma história construída, preservada e narrada no existir em um lugar, por oposição a quem "chega de fora". 


\section{CONSIDERAÇÕES FINAIS}

Assim, saibamos reconhecer a existência de um fundamento de autoctonia que revela o próprio ser da comunidade tradicional que estaremos considerando nestes estudos. Este reconhecimento que com facilidade é revelado a quem chega e pergunta, remete a palavras de José de Souza Martins re-escritas aqui muitas linhas acima.

Sob o olhar da frente pioneira, quem estava e habitava "aqueles sertões vazios" é invisível porque se confunde com a própria natureza que não soube "trabalhar". Ou é "uma gente atrasada" (= tradicional) porque deixou-se justamente ficar "à margem da história". Isto é: da história do que imaginam que somente eles fazem história e, depois, a pensam e escrevem.

Sob o olhar das frentes de pobres que, empurrados, chegam "ali", tradicionais se tornaram eles, se não se incorporaram aos serviços ou projetos dos "modernos", ao lado dos que, antes deles - e com histórias e estórias passadas e presentes não muito diversas - já estavam "aqui".

Sob outro olhar, o das "vítimas", as comunidades tradicionais são o que existia antes quando, em um tempo "antes", pessoas, famílias, teias de parentes de parceiros, etnias e povos já "ali estavam" quando os "outros" chegaram. Aqueles que, em direção oposta, foram "descobertos" - quando a sua existência em um espaço natural é percebida e levada em conta - desbravados, conquistados, dominados, submetidos, cercados e, não raro, expulsos em direção a outra fronteira provisória.

E esta deve ser a primeira característica da comunidade tradicional. Ela não está tanto em sua tradicionalidade, pois este atributo sim, parece ser bastante pouco aplicável como um diferenciador de modalidades de grupos sociais, de formas de povoamento, de modos de vida, de culturas e de identidades. A autonomia, a autoctonia e a cultura de resistência, sim. $\mathrm{O}$ fato de uma comunidade de povoadores de um território poder reclamar o "ser daqui", ou "estar aqui" desde tempos imemoriais ou, pelo menos, desde "a chegada do estranho". Do "outro" vindo de fora.

A comunidade autóctone pode proclamar como um estatuto de perenidade, que sempre esteve em um lugar até agora habitado por descendentes de ancestrais; que ocupa um lugar de vida e trabalho do qual, mesmo não sendo em sua origem a unidade pioneira, é a quem pode atestar ou rastrear uma presença antecedente a de outras frentes de povoamento posteriores. Ela pode reclamar uma autoctonia relativa: não é pioneira nem a mais antiga, mas habita um território partilhado com outras unidades sociais de povoamento remoto, comprovada ou imaginariamente antecedente de longo ou médio tempo à chegada de outras frentes de povoamento.

Ousemos ver e pensar por um momento não o que está nos estudos científicos, cada um de modo geral centrado sobre uma modalidade de "acontecer no campo", mas o que se dá a ver quando, com olhos abertos e desarmados percorremos uma região rural entre cidades. Procuremos colocar lado a lado e depois aproximar ou opor as mais diferentes formas ancestrais e atuais de ocupação de territórios fora-da-cidade. Lancemos mão, em primeiro lugar, de critérios simples de tempo-eespaço. Coloquemos, então, de um lado, aquelas povoações, comunidades sobre as quais tempos aplicado o qualificador "tradicional".

Em um vôo mais alto e ousado, coloquemos de um lado as comunidades étnicas: as de povos indígenas e as de remanescentes quilombolas, sempre a meio caminho entre a comunidade étnica e a comunidade tradicional regional. Pensemos agora um ousado contraponto. Ele poderá parecer aqui um convidado indevido. No entanto, ele "aí está" e multiplica-se ao redor das cidades e nos entremeios entre uma cidade e outra de maneira muito acelerada. O capital a semeia sobre terrenos que antes foram fazendas ou "áreas vazias", e o desejo "classe A" de viver uma vida ao mesmo tempo urbana-e-rural, "ecologicamente correta e feliz" e sumamente protegida. Torna-a um lugar fabricado extremamente valorizado e ela se constitui das modernas comunidades-condomínios em que o próprio termo "comunidade" pode ser indevido.

E é sobre este "viver-como-na-cidade" habitando um recanto de "natureza exuberante preservada", um "lugar no campo", mas distante e protegido do rural, que se edificam os projetos e as promoções mais caras destinadas a quem possa pagar pelo luxo de voltar ao campo e à natureza 
sem abrir mão do conforto mais exigente dos bairros ricos de uma cidade. Raros ainda mesmo em Montes Claros, eles se multiplicam entre os quatro pontos cardeais de cidades-cerrado, como Goiânia, Campo Grande e, claro, Brasília. No mais, em quase tudo o que nos importa tais condomínios de reocupação "nobre" do campo pela cidade constitui o oposto do que nos espera no próximo parágrafo.

Podendo parecer semelhantes, para quem olha de longe, diversas das comunidades-condomínio, podemos colocar as comunidades de opção. Em boa medida elas são constituídas por pessoas vindas da cidade e animadas pelo projeto de realizarem no campo uma experiência de vida alternativa. Uma vida fortemente centrada em um imaginário utópico de comunidade ideal centrada em uma opção de produção de bens da terra por meios ecologicamente corretos, eugenicamente sadios e socialmente solidários. Ecovilas, pequenas áreas de agricultura orgânica e corporada são seus bons exemplos. Algumas, as mais antigas, podem ser originadas de unidades confessionais e/ou religiosas. Não esqueçamos que práticas de relação sustentável com o ambiente e de agricultura orgânica (em suas diferentes alternativas) associam-se aqui e ali a projetos comunitários em assentamentos de reforma agrária e mesmo em algumas comunidades tradicionais. Todo um novo e promissor movimento centrado em simplicidade voluntária e na socioeconomia solidária os anima.

Podemos situar aqui dois tipos de néo-comunidades que, juntas, reclamam o termo: "popular", a elas atribuído com freqüência. No entanto, sendo povoadas, vividas e pensadas por pessoas, famílias e grupos de vecindário entre pequenos proprietários lavradores de terra - os "camponeses" de nossos estudos - ou por unidades sociais diferenciadas quanto ao trabalho prioritário, elas se separam segundo outro critério.

Ao ocuparem territórios ribeirinhos e sertanejos não raro próximos em sua geografia e em sua condição de pobreza, essas néo-comunidades possuem momentos de ocupação de territórios e histórias de seus processos bastante diversas. Estamos agora diante de comunidades de ocupação, como os acampamentos provisórios e os assentamentos dos movimentos de reforma agrária. E estamos diante de comunidades de expropriação. Elas são aquelas ocupadas por populações e comunidades "deslocadas" por efeito de construções de barragens, pela constituição de áreas de parques e reservas naturais ou outros processos de re-significação de territórios. Quase sempre as populações "desalojadas" são levadas para algum lugar ainda rural, ou já urbano pré-escolhido pelo poder público.

Voltemos à comunidade popular. É ela o nosso sujeito aqui. Uma pequena síntese poderia ser tentada agora. Ela poderá repetir idéia e mesmo indicadores classificatórios já vistos. Mas que nos sirva com uma síntese provisória de todo o caminho percorrido até aqui

Se os próprios sujeitos das diferentes comunidades tradicionais, entre palavras e apelos diversos, formulassem os fundamentos de seus direitos a viverem onde vivem, a trabalharem a terra que trabalham, a partilharem "ali", um modo de vida próprio e a transferirem aos seus herdeiros a casa, a comunidade e o território que reconhecem haver herdado de seus antepassados, ou ocupado antes "da chegada dos outros", quais seriam eles?

$1^{\circ}$. Eles são os atuais povoadores do lugar e habitantes de um espaço natural tornado, em um tempo anterior que se prolonga a um presente, um lugar social: uma comunidade. São aqueles que se reconhecem e identificam como herdeiros legítimos, através de relações contínuas de parentesco e descendência, de ancestrais fundadores de um lugar: a) porque sempre existiram ali antes da chegada reconhecida de qualquer outro grupo humano; b) porque seus ancestrais foram os primeiros a virem de algum outro lugar para aquele, de que são considerados como fundadores. Tais ancestrais podem ser identificados como: uma pessoa, uma família, um pequeno grupo de famílias nucleares de uma mesma parentela, algumas famílias originalmente não ligadas por laços de parentesco, mas depois entretecidas como uma rede de parentela, a partir de uniões conjugais ou de outra natureza após a chegada ao lugar de origem.

$2^{\circ}$. Eles próprios são os que, chegados de outro lugar antecedente a um novo lugar, ali se fixaram e formaram uma comunidade original, mesmo que em tempos não remotos. Notemos que 
neste caso, tal como no anterior, mesmo quando é de algum modo lembrada uma pré-existência anterior de outros povos, como grupos indígenas - cujo nome tribal pode ser identificado ou não - são negados ou são esquecidos os seus direitos sobre o território: a) porque o "povo" anterior é tido como não mais existente; b) porque acredita-se que em tempos anteriores ou contemporâneos aos da chegada dos ancestrais fundadores da comunidade, o povo indígena originário abandonou o lugar.

$3^{\circ}$. Eles são os que, depois de estabelecidos “aqui”, geraram uma população local através da reprodução física de descendentes, em uma comunidade local definida por um duplo "estar aqui": a) ela se reproduz fisicamente em um lugar socialmente habitado; b) ela estabelece utilitária e simbolicamente um espaço delimitado como um território próprio da comunidade, como ou sem divisas restritas e, não raro, sob ameaça de expropriação.

$4^{\mathrm{o}}$. Através do trabalho produtivo de seus ancestrais fundadoras até o do da geração atual, eles se reconhecem como os agentes diretos de socialização da natureza em um lugar "aqui". Assim, um espaço tido como anteriormente "vazio", "selvagem", "ermo", "abandonado", torna-se aos poucos e de maneira compreendida como irreversível, um lugar de natureza socializada e capaz de acolher, devido ao trabalho humano de sua transformação, uma comunidade de pessoas, famílias e redes de parentesco e vizinhança. Em tempos originais, ou até o momento presente, este trabalho pessoal, familiar e coletivo é tido como realizado sem ou quase-sem o concurso de "ajudas" exteriores à comunidade.

$5^{\circ}$. Eles são aqueles que, ao longo de tempo e de maneira concomitante com o exercício diferenciado do trabalho produtivo criaram espaços de vida e atribuíram a eles símbolos, sentimentos e significados que, mesmo provenientes de modos de vida e de culturas regionais, adquirem "aqui" um valor de sentido específico, próprio e "nosso". Um lugar ganha um nome. Seus locais de natureza ou de "povoado" virão uma cartografia comunitária, entre o nome atribuído a uma árvore e o dado a uma capela erigida, ou a um cemitério. Há, com o passar do tempo, um calendário que se amplia da pessoa à família, dela à teia de parentes-e-vizinhos, parceiros de vida. Um calendário-cartografia de práticas, de celebrações, de marcações culturais do passar do tempo, entre trabalho e festa, que, em boa medida demarca também os tempos pessoal e coletivamente culturais com que uma identidade do "ser daqui" se constrói esse modifica.

$6^{\circ}$. Ao longo de gerações eles são os que estabeleceram, transformaram e partilha um forte sentido simbólico e identitário do "ser daqui". Quem "vive aqui" - fora as chegantes posteriores, claramente reconhecidos pelos autóctones - e "é daqui" identifica-se, antes do reconhecer-se como sendo "do município de Ibiaí", do Norte de Minas, de Minas Gerais ou do Brasil, historicamente como descendente de um sujeito ou uma unidade social fundadora e geograficamente como pertencendo a "este lugar". Neste sentido, existe uma clara diferença entre que "é daqui" por autoctonia de descendência e por vivência atual "aqui", e quem "veio de fora" e se estabeleceu - por casamento ou outras razões".

$7^{\circ}$. Eles se reconhecem como os que herdaram e/ou geraram a tessitura das reciprocidades internas de bens e serviços entre integrantes de grupos domésticos, de redes de parentes e de outras estruturas com graus variáveis de formalidade e duração: teias de vizinhança, equipes de trabalho corporado, equipes de trabalho ritual, grupos de idade, de interesse ou de outras formas e motivos de afiliação. O próprio sempre complexo tabuleiro de alianças e conflitos, de preferências e evitações, de formação de unidades de trocas e reciprocidades, aos poucos se constrói. E, mais do que um território que se habita, esta é a terra social e simbólica que se vive.

$8^{\circ}$. Ao longo do tempo e de acordo com padrões variáveis de troca autônoma, de dependência relativa, de bens e de serviços em diferentes situações de trabalho subalterno ou não, eles esta- 
beleceram e preservaram relações de intercâmbio com outras comunidades de igual condição e cultura, ou com diferentes modalidades de sociedades-polo de mercado e poder.

$9^{\circ}$. Eles herdaram como uma comunidade, ou criaram e transformaram ao longo dos anos e através de gerações, sistemas apropriados ou próprios de saberes - as diferentes ciências populares - de representação da realidade e de atribuição de valores de conduta e de atribuição de identidade. Enfim, de tudo aquilo que no passar dos anos sustentou como sistemas de saber de práticas do fazer e de éticas do agir, a reprodução física e social da comunidade. E aquilo a que hoje, com uma importância teórica, política e prática tendemos a atribuir hoje o nome de patrimônio cultural imaterial

$10^{\circ}$. Eles se reconhecem como apropriadores e/ou criadores por conta própria - mas sempre dentro de padrões culturais de âmbito regionalmente mais amplos do que "uma comunidade" - de diferentes modalidades e sistemas de reprodução da cultura, através da circulação de símbolos, saberes, sentidos, significados e valores de sociabilidade entre pessoas de uma mesma geração e, de maneira especial, através da socialização de crianças, adolescentes e jovens.

$11^{\circ}$. Eles criaram formas originais ou aprendidas com outros de associações internas - de uma equipe corparada de trabalho da pesca a uma equipe de trabalho simbólico da Dança de São Gonçalo, e delas a um time de futebol - assim como (por iniciativa própria ou através de negociações com "os de fora") acolheram e incorporaram à "vida da comunidade" algumas unidades sociais vindas de setores externos da sociedade civil (de igrejas a raras ONGs) ou do poder público (da escola ao posto de saúde).

$12^{\circ}$. Eles possuem e preservam a memória de uma história já passada ou ainda presente, de situações de organização e mobilização de alternativas de resistência e/ou de luta frente a processos de cercamento de terras, de expropriação parcial de território, de ameaças de expulsão "do lugar", ou atos semelhantes de ameaça aos direitos de liberdade e de integridade de posse e uso da comunidade.

\section{AGRADECIMENTOS}

Estes escritos em primeiro momento foram uma parte inicial do longo relatório do Projeto Opará: tradição e mudança entre comunidades tradicionais ribeirinhas do São Francisco em Minas Gerais - uma abordagem seqüencial e multidisciplinar, financiado pelo CNPq Processo 400150/20085 e pela FAPEMIG APQ-5995-5.06-07. A pesquisa foi desenvolvida no Norte de Minas Gerais em parceria entre a Universidade Federal de Uberlândia e a Universidade Estadual de Montes Claros.

\section{REFERÊNCIA BIBLIOGRÁFICA}

ALMEIDA, A. W. Os quilombos e as novas etnias. In: LEITÃO (org.) Direitos Territoriais das Comunidades Negras Rurais. São Paulo: Instituto Socioambiental, 1999.

ALMEIDA, A. W. Terras tradicionalmente ocupadas. Revista Brasileira Estudos Urbanos e Regionais, v.6, n.1 / maio 2004.

ARROYO, Leonardo. A Cultura popular em Grande Sertão: Veredas. Rio de Janeiro: José Olympio, 1984. 315p.

BAUMAN, Ziygmunt. Comunidade - a busca por segurança no mundo atual. Rio de Janeiro: Editora Zahar, 2003.

BELSHAW, Cyril. Troca tradicional e mercado moderno. Rio de Janeiro: Jorge Zahar, 1968.

BHABHA, Homni. O lugar da cultura. Belo Horizonte: Editora da UFMG, 1998. 
BRANDÃO, Carlos Rodrigues. Memória-Sertão - cenários, cenas, pessoas e gestos nos sertões de João Guimarães Rosa e de Manuelzão. São Paulo: Cone Sul / Editora da Universidade de Uberaba, 1998.

BRANDÃO, Carlos Rodrigues. Relatório final do Projeto Tempos e espaços nas comunidades rurais do Alto e Médio São Francisco - Minas Gerais. Uberlândia: UFU, 2009.

CAA NM - Centro de Agricultura Alternativa do Norte de Minas. RECONVERSÃO AGROEXTRATIVISTA: da monocultura do eucalipto para sistemas agrossilvipastoris. Das Comunidades dos Gerais de Rio Pardo de Minas aos Poderes Públicos Municipal, Estadual e Federal. Rio Pardo de Minas, 2004.

Carta manifesto das mulheres e homens Vazanteiros. Encontro dos Povos das Águas e das Terras Crescentes do São Francisco. Manga, Ilha das Ingazeiras, 2006.

CEDEFES - Centro de Documentação Eloy Pereira da Silva. Comunidades Quilombolas de Minas Gerais no Século XXI - História e Resistência. Belo Horizonte: Autêntica/CEDEFES, 2008.

CHAUÍ, Marilena. Cidadania Cultural: o direito à cultura. São Paulo: Brasiliense, 1990.

CUNHA, Manuela Carneiro da. Cultura com aspas. São Paulo: Editora Cosac Naify, 2009.

DIEGUES, Antônio Carlos (org.). Etnoconservação. São Paulo: Hucitec, 2000.

DIEGUES; Antonio Carlos e ARRUDA; Rinaldo S.V. (orgs.) Saberes tradicionais e biodiversidade no Brasil. Brasília: Ministério do Meio Ambiente; São Paulo: USP, 2001.

DIEGUES, A. C. As Populações Tradicionais: Conceitos e Ambigüidades. In: DIEGUES, A. C. O Mito moderno da natureza intocada. 5ed. São Paulo: Hucitec, 2004.

ELIAS, Norbert. A sociedade dos indivíduos. Rio de Janeiro: Editora Jorge Zahar, 1994.

FELDMAN-BIANCO, Bela e RIBEIRO, Gustavo Lins. Antropologia e Poder: Contribuições de Eric Wolf. São Paulo. Unicamp, 2003. P

FOSTER, George M. Tzintzuntzan. Los campesinos mexicanos en un mundo en cambio. México: Fundo da cultura econômica, 1972.

FOSTER, George M. Tzintzuntzan. As culturas tradicionais e as mudanças técnicas. México: Fundo de Cultura Econômica, 1964.

GOMES, Ramonildes Alves. De sitiantes a irrigantes: construção identitária, conversão e projetos de vida. In: GODOI, Emília Pietrafesa de; MENEZES, Marilda Aparecida de e MARIN, Rosa Acevedo. Diversidade do campesinato: expressões e categorias. Volume II: Estratégias de reprodução social. São Paulo: NEAD, Ministério do Desenvolvimento Agrário e Editora da UNESP, 2009.

HELLER, Agnes. Sociologia de la vida cotidiana. Barcelona: Peninsola. 1977.

KROEBER, Alfred. Anthropology. Harcourt-Brace, Nova York. 1948.

MAFFEZOLI, Michel. A transfiguração do político - a tribalização do mundo. Porto Alegre: Editora Sulina, 1997.

MALINOWSKI, Bronislaw. Argonautas do Pacífico Ocidental: Um Relato do Empreendimento e da Aventura dos Nativos nos Arquipélagos da Nova Guiné Milanésia. Traduções de Anton P. Carr e Lígia Aparecida Cardieri Mendonça, revista por Eunice Ribeiro Durham - São Paulo: Abril cultural, 1976. Coleção os pensadores.

MARTINS, José de Souza. Capitalismo e tradicionalismo (estudos sobre as contradições da sociedade agrária no Brasil). São Paulo: Pioneira, 1975.

MARTINS, José de Souza. Fronteira: a degradação do Outro nos confins do humano. São Paulo: EDITORA HUCITEC, 1997.

Ministério do Meio Ambiente. Biodiversidade Brasileira - avaliação e identificação de áreas e ações prioritárias para conservação, utilização sustentável e repartição de benefícios da biodiverdade brasileira. vol. 5 série: Biodiversidade - Cerrado e Pantanal, Brasília: MNA, 2002.

PARANHOS, Lucíola da Silva. Tecendo a rede e pescando o peixe - desenvolvimento e redes sociais: a articulação local-global no norte de Minas. Montes Claros: Unimontes, 2006 (Dissertação de Mestrado) PIERRE CASTILE, Georges. Cherán: la adaptación de uma comunidad tradicional de Michoacan. México DF: Instituto Nacional Indigenista, 1974. 
PIERSON, Donald. O Homem no Vale do São Francisco. Rio de Janeiro: minter/SUVALE, 1972, Tomo II. PORTO GONÇALVES, Carlos. V. As minas e os Gerais: Breve ensaio sobre o desenvolvimento e sustentabilidade a geografia de Norte de Minas. In: LUZ, Claudia; DAYRELL, Carlos (org.). Cerrados e Desenvolvimento: tradição e atualidade. Montes Claros: UNIMONTES: 2000. p. 19-45.

RABELO, Mônica Celeida. Gerais a dentro e a fora: identidade e territorialidade entre Geraizeiros do Norte de Minas Gerais. ICS/DAN, UNB/ Brasília: 2009, (tese de doutorado em antropologia)

REDFIELD, Robert. The primitive world and its transformations. Cornell Univ. Press, Ithaka, NY.1968. ROSA, João Guimarães. Grande sertão: veredas. $7^{\mathrm{a}}$ edição. Rio de Janeiro: Livraria José Olympio Editora, 1970.

ROSA, João Guimarães. Manuelzão e Miguilim. (Noites do sertão). Rio de Janeiro: Nova fronteira, 2001. ROSA, João Guimarães. Primeiras Histórias. Rio de Janeiro: Nova Fronteira,1998.

SAINT-HILAIRE, Auguste de. Viagem às nascentes do rio São Francisco. 2 ed. Belo Horizonte: Itatiaia, 2004. $190 \mathrm{p}$.

SANTOS, Ana Flávia Moreira. Do terreno dos caboclos do Sr. São João à Terra

SORRE, M. Geografia. São Paulo: Ática, 1984.

WOLF, Erik. Closed comporate peasant communities in Mesoamerica and Central Java. In: Peasant society, editado por Jack M. Potter, Little, Brown and Company. Boston, 1967, ps. 299 a 317.

WOORTMANN, Klaas. "Com parente não se neguceia". O campesinato como ordem social. In: Anuário Antropológico. Brasília: Editora Universidade de Brasília, n. 87, 1990.

Trabalho enviado em fevereiro de 2012 Trabalho aceito em março de 2012 